OPEN ACCESS

Edited by:

Xun Zhong,

Yangtze University, China

Reviewed by:

Huanqiang Yang,

Yangtze University, China

Dong Xiong,

China University of Petroleum, China

*Correspondence:

Zhong $\mathrm{Li}$

bridges908@163.com

Specialty section:

This article was submitted to Advanced Clean Fuel Technologies,

a section of the journal

Frontiers in Energy Research

Received: 13 January 2022

Accepted: 27 January 2022

Published: 16 February 2022

Citation:

Li Z, Wu Y, Xie R and Wu Z (2022) Influence of the Casing Eccentricity on the Cement Sheath Sealing Integrity in

the Tie-Back Interval Under the Complex Temperature and Pressure

Conditions of Deep-Water Oil and

Gas Wells.

Front. Energy Res. 10:853793.

doi: 10.3389/fenrg.2022.853793

\section{Influence of the Casing Eccentricity on the Cement Sheath Sealing Integrity in the Tie-Back Interval Under the Complex Temperature and Pressure Conditions of Deep-Water Oil and Gas Wells}

\author{
Zhong Li ${ }^{*}$, Yi Wu, Renjun Xie and Zhiqiang Wu \\ CNOOC Research Institute Co., Ltd., Beijing, China
}

The integrity of cement sheath seals in casing connection sections is an important part of preventing air channelization. It is of great significance to evaluate the failure mechanism of cement sheath seals in casing connection sections under complex temperatures, pressures, and casing eccentricities. Based on the self-developed high-temperature and high-pressure full-size casing connection period of the cement sheath seal integrity evaluation device and the casing loading/unloading casing eccentricity influence on the cement sheath seal failure under the experimental conditions, it is concluded that the casing pressure changes, annulus preset pressure, and casing eccentricity influence the law of cement sheath seal integrity. The results show that the following: (1) Casing eccentricity has an important influence on the failure of the cement sheath seal when the casing is loaded, and to ensure the integrity of the cement sheath seal the casing should be greater than $75 \%$; (2) in the case that the annular pressure is not set, casing eccentricity has little influence on the integrity of the cement annular seal during casing unloading, and sealing failure occurs when pressure unloading is $15-20 \mathrm{MPa}$; (3) when there is a preset pressure in the annulus, casing eccentricity has a great influence on seal failure during unloading. The greater the preset pressure in the annulus is, the better the seal integrity of the cement annulus. The research results provide an important basis for ensuring the integrity of cement sheath seals in casing connection sections.

Keywords: high temperature and high pressure, casing tieback, cement sheath, casing eccentricity, integrity, fullscale experiment

\section{INTRODUCTION}

As a key part of oil and gas well barriers, cement sheaths are of great significance to ensure the integrity of wellbores (Song et al., 2002; Pang et al., 2009; Yang et al., 2019). In deep-water oil and gas wells, high temperature, high pressure, and narrow pressure windows are typical characteristics. The cementing quality of the open hole interval is often poor because of the lower displacement during cementing construction with a narrow pressure window. In this case, the sealing integrity of the cement sheath in the casing tieback interval is the key to 
TABLE 1 | Cement sheath seal failure evaluation device.

\begin{tabular}{|c|c|c|c|c|}
\hline Literature source & Wellbore system composition & Shaft size & $\begin{array}{c}\text { Casing } \\
\text { eccentricity }\end{array}$ & $\begin{array}{l}\text { Temperature and } \\
\text { pressure }\end{array}$ \\
\hline Zeng et al. [Zeng et al. (2019]) & Casing + Cement sheath + Casing & $7 \mathrm{in}+8.625$ in & 0 & $150^{\circ} \mathrm{C}$ \\
\hline Li Yanjun et al. [Li et al. (2020)] & Casing + Cement sheath + Formation & $\begin{array}{l}7 \text { in+8.625 } \\
\text { in }+15.75 \text { in }\end{array}$ & & $200^{\circ} \mathrm{C}$ \\
\hline Yuan et al. (2013) (Yuan et al., 2013) & $\begin{array}{l}\text { Inner casing + Cement sheath + Resin } \\
\text { glass casing }\end{array}$ & $2.60 \mathrm{in}+2.76 \mathrm{in}$ & & $150^{\circ} \mathrm{C}$ \\
\hline Shadravan et al. (2015) (Shadravan et al., 2015) & Casing + Cement sheath + Casing & $1 \mathrm{in}+1.25 \mathrm{in}$ & & $232^{\circ} \mathrm{C}$ \\
\hline Teodoriu et al. (2010) (Teodoriu and Krut, 2010) & Casing + Cement sheath + Casing & $5.5 \mathrm{in}+10.75 \mathrm{in}$ & & $\begin{array}{l}\text { Normal atmospheric } \\
\text { temperature }\end{array}$ \\
\hline $\begin{array}{l}\text { De Andrade et al. (2014) (De Andrade et al., } \\
\text { 16801220) }\end{array}$ & Casing + Cement sheath + Formation & $\begin{array}{l}1.18 \mathrm{in}+1.5 \\
\text { in }+6.89 \text { in }\end{array}$ & & $200^{\circ} \mathrm{C}$ \\
\hline $\begin{array}{l}\text { Goodwin and Crook (1992) (Goodwin and } \\
\text { Crook, 1992) }\end{array}$ & Casing + Cement sheath + Casing & $5.5 \mathrm{in}+7.625 \mathrm{in}$ & & $176^{\circ} \mathrm{C}$ \\
\hline
\end{tabular}

preventing the phenomenon of gas channeling. The cement sheath in the casing connection section of HPHT oil and gas wells not only faces the complex formation environment of high temperature and high pressure, but is also affected by the initial cementing quality and subsequent construction conditions, so the risk of sealing failure of the cement sheath in HPHT wells is very high. The occurrence of an annulus pressure in Central Sichuan (Su et al., 2014), South China Sea (Xie et al., 2016) and Tarim (Yang et al., 2018) also means that the sealing integrity of the cement sheath in the casing tieback interval has been damaged. The problem of annular pressure has brought serious hidden dangers to the safe development of petroleum resources (Gao and Liu, 2019). Therefore, it is urgent to study the failure mechanisms of cement sheath seals and find feasible solutions.

The influencing factors and rules of cement seal integrity are complex. Existing studies show that different seal failures of cement sheaths, such as compression failure, tensile failure, and cementation failure (Andrade et al., 2016; De Andrade and Sangesland, 2016), may occur under such conditions as temperature changes in the wellbore, casing pressure tests and density reductions in the casing (Liu et al., 2014; Rossine Medeiros de Souza et al., 2018). The elastic modulus of the cement sheath, initial stress, bonding strength and other factors have a great influence on the sealing ability of the cement sheath (Ladva et al., 2004; Wang and Taleghani, 2014; Arjomand et al., 2018). To solve this problem, the experimental evaluation of the seal failure of cement sheath in the casing connection section is beneficial for exploring the influence rules of different factors on the seal integrity of cement sheaths and put forward specific optimization suggestions, which is of great significance for solving the problem of seal failure of cement sheath. Currently, in terms of the integrity of cement sheath seals, several sets of failure evaluation devices for cement sheath seals have been developed. Their technical parameters, experimental capacities and main experimental purposes are shown in Table 1:

However, most of the above evaluation experiments are performed with equal-scale reduction devices, which require a complex stress equivalent conversion. In addition, casing

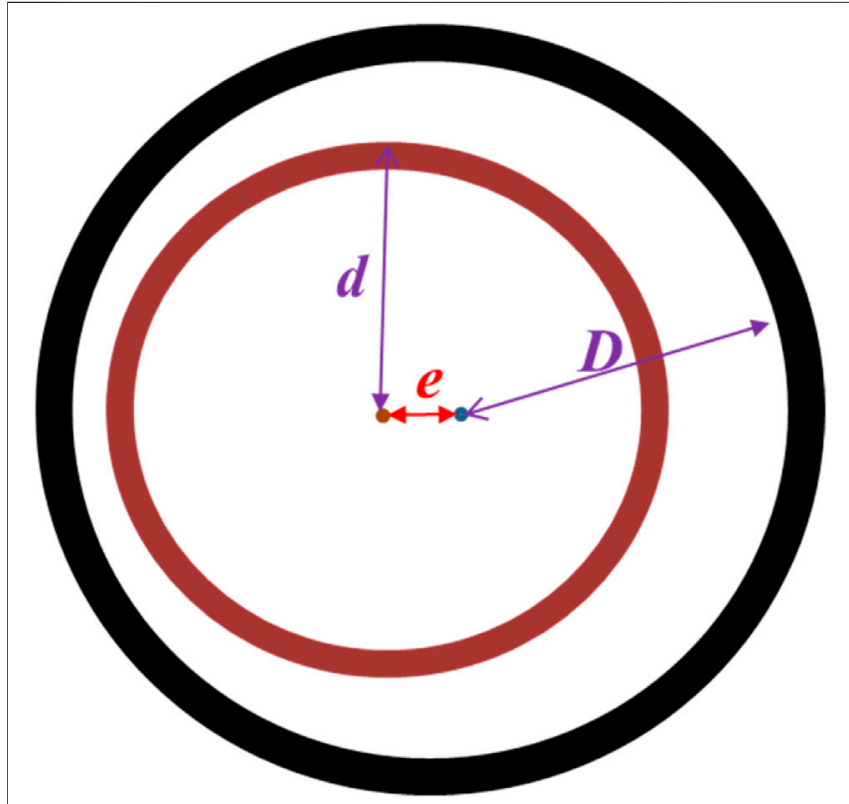

FIGURE 1 | The schematic diagram of casing eccentric.

eccentricity is ignored during the experimental process. At the same time, existing studies show that casing centralization has a great influence on the stress state of cement sheaths (Liu et al., 2018). As such, a set of full-scale devices for cement sheath seal integrity evaluation at high temperature and high pressure returns and eccentric casing is developed. The influence of the casing eccentricity on the cement sheath seal failure under pressure loading/unloading in the casing is studied.

This paper is organized as follows. Section 2 describes the cement sheath seal failure evaluation experiment, including the experimental device, the experimental materials to be utilized, and the experimental scheme for the performed experiments. Section 3 describes the results of the experimental investigations, including the complex temperature and pressure conditions and the annular reserved pressure under different casing eccentricities, followed by conclusions in Section 4 . 
TABLE 2 | The casing centering $\delta$ and their corresponding eccentricity e.

\begin{tabular}{lccc}
\hline $\mathbf{D / m m}$ & $\boldsymbol{d} / \mathbf{m m}$ & $\boldsymbol{e} / \mathbf{m m}$ & $\boldsymbol{\delta}$ \\
\hline 216.8 & 177.8 & 19.5 & 0 \\
& & 9.75 & 0.5 \\
& 6.435 & 0.67 \\
& 4.875 & 0.75 \\
& 0 & 1
\end{tabular}

\section{CEMENT SHEATH SEAL FAILURE EVALUATION TEST OF THE CASING TIEBACK INTERVAL}

\subsection{Experimental Device}

According to the complex environment of cementing cement sheaths in high-temperature and high-pressure oil and gas wells and the conditions of casing eccentric wellbores, combined with the experimental test method of annular air channeling after cement sheath sealing failure, a set of sealing integrity evaluation devices for casing eccentric cement sheaths in high-temperature and highpressure full-size return sections is developed. The experimental device consists of a full-size inner and outer casing, a heating control system, an annular pressurization system, an inner casing pressurization system, a gas pressurization system, eccentric flange, etc. The inner and outer casings are composed of 177.8 and $244.5 \mathrm{~mm}$ casings, respectively. The temperature control system can control a $20-200^{\circ} \mathrm{C}$ temperature, the annulus pressurization system can control a $0-40 \mathrm{MPa}$ annulus pressure, and the inner casing pressurization system can control a $0-70 \mathrm{MPa}$ casing pressure. The gas pressurization system can control a $0-10 \mathrm{MPa}$ gas pressure. The eccentric flange can adjust the casing centering $\delta$ to $50 \%, 67 \%, 75 \%$ and $100 \%$. The schematic diagram of casing centering is shown in Figure 1 and Table 2.

The device structure diagram and general assembly diagram are shown in Figure 2.

1. Lower flange; 2 . Heating rod; 3 . Cement sheath; 4 . Inner casing; 5. Outer casing; 6. Eccentric flange.

\subsection{Experimental Materials}

The high temperature resistant cementing slurry system for casing back connection of Lingshui 25-1 Deepwater High Temperature and high pressure gas field in the South China Sea is selected as the experimental material, with a density of $2.15 \mathrm{~g} / \mathrm{cm}^{3}$. Its composition is shown in Table 3 .

\subsection{Experimental Scheme}

\subsubsection{Experimental Scheme Setting}

To evaluate the influence of casing eccentricity on cement sheath seal failure, the influence of casing centering on cement sheath seal failure under different loading and unloading pressures is set. The experimental scheme is shown in Table 4.

\subsubsection{Experimental Steps}

Comprehensively considering the complex temperature and pressure changes in the casing, casing eccentricity and other factors, cement sheath seal failure is evaluated based on the gas channeling differential pressure method, where the following experimental steps are set:

Step (1): install the base, lower the casing flange and lower the eccentric flange, and connect the inner and outer casing with the eccentric flange to form an annular space; Step (2): prepare the cement slurry according to the GB/T 191392012 test method for oil well cement, and inject the prepared cement slurry into the annular space formed by the inner and outer casing (the cement slurry accounts for $85-95 \%$ of the volume of the annular space). Add a certain amount of white oil to the upper end face of the cement slurry to prevent the cement slurry from boiling due to the high temperature; Step (3): install the upper casing flange and upper eccentric flange, connect all high-pressure pipelines, and fill the inner casing with heat transfer oil; Step (4): according to the experimental scheme, set the curing temperature of the cement slurry, pressure in the casing and curing time, ensure that the pressure at the upper end of the cement sheath is $2 \mathrm{MPa}$ during heating, and release the pressure value after curing; Step (5): open the air inlet valve at

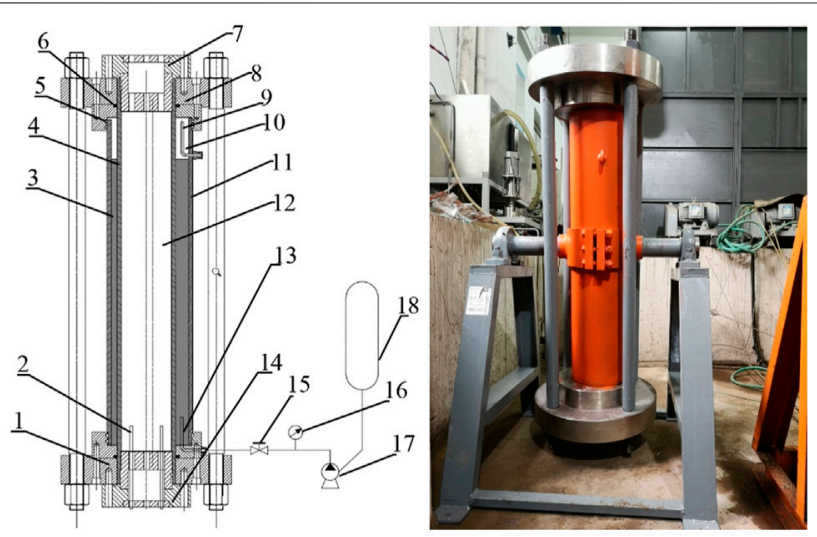

1. Lower flange; 2. Heating rod; 3. Cement sheath; 4. Inner casing; 5 . Outer casing; 6 . Eccentric flange

FIGURE 2 | Sealing integrity evaluation device for an eccentric cement sheath of a casing in a high-temperature and high-pressure full-size return section. 
TABLE 3 | Formula of the cement slurry system for the experiment.

Mass percentage

(\%)

\section{Freshwater}

Class G oil well cement

Heat stabilizer

Self-repairing material

Anti-channeling reinforcing agent

Latex defoamer

Fluid loss additive

Latex

Dispersant

High temperature retarder

Medium temperature retarder
40.83

$\begin{array}{cc}40.83 & 5.43 \\ 100 & 13.29 \\ 50 & 6.64 \\ 5 & 0.66 \\ 2 & 0.27 \\ 1 & 0.14 \\ 3.5 & 0.47 \\ 8 & 1.06 \\ 1 & 0.14 \\ 1.5 & 0.20 \\ 0.5 & 0.07\end{array}$

TABLE 4 | Effect of casing eccentricity on cement sheath seal failure.

\begin{tabular}{|c|c|c|}
\hline Casing centering & $\begin{array}{c}\text { Cyclic load in casing } \\
\text { (MPa) }\end{array}$ & $\begin{array}{l}\text { Unloading in casing } \\
\text { (MPa) }\end{array}$ \\
\hline $50 \%$ & No & $50 \rightarrow 45 \rightarrow 40 \rightarrow 35 \rightarrow \ldots \ldots$ \\
\hline \multicolumn{3}{|l|}{$67 \%$} \\
\hline \multicolumn{3}{|l|}{$75 \%$} \\
\hline \multicolumn{3}{|l|}{$100 \%$} \\
\hline \multirow[t]{2}{*}{$50 \%$} & $0 \rightarrow 30 \rightarrow 0 \rightarrow 40 \rightarrow 0 \rightarrow$ & No \\
\hline & $50 \rightarrow 0 \rightarrow 60 \rightarrow 0 \rightarrow 70 \rightarrow 0$ & \\
\hline \multirow[t]{2}{*}{$67 \%$} & $0 \rightarrow 30 \rightarrow 0 \rightarrow 40 \rightarrow 0 \rightarrow$ & No \\
\hline & $50 \rightarrow 0 \rightarrow 60 \rightarrow 0 \rightarrow 70 \rightarrow 0$ & \\
\hline \multirow[t]{2}{*}{$75 \%$} & $0 \rightarrow 30 \rightarrow 0 \rightarrow 40 \rightarrow 0 \rightarrow$ & No \\
\hline & $50 \rightarrow 0 \rightarrow 60 \rightarrow 0 \rightarrow 70 \rightarrow 0$ & \\
\hline \multirow[t]{2}{*}{$100 \%$} & $0 \rightarrow 30 \rightarrow 0 \rightarrow 40 \rightarrow 0 \rightarrow$ & No \\
\hline & $50 \rightarrow 0 \rightarrow 60 \rightarrow 0 \rightarrow 70 \rightarrow 0$ & \\
\hline
\end{tabular}

the bottom of the experimental device, adjust the air inlet pressure to $0.1 \mathrm{MPa}$, change the temperature and pressure in the casing according to the experimental scheme, observe whether there are bubbles on the upper end face of the cement sheath, and record the change in the air inlet pressure, as shown in Figure 3.

\section{EXPERIMENTAL RESULTS AND ANALYSIS}

\subsection{Pressurization in Casing}

According to the experimental scheme in Table 2, the experiment on the influence of loading in the casing on the sealing integrity of the cement sheath under the condition of casing eccentricity is performed. The experimental process is shown in Figure 4:

The experimental results are shown in Table 5. The results show that for the two types of casing centricities of $50 \%$ and $67 \%$, when the casing is pressurized from 0 to $60 \mathrm{MPa}$ and unloaded to $0 \mathrm{MPa}$, gas channeling occurs at the interface between the inner casing and the cement sheath (as shown in Figure 4). For 75 and $100 \%$ casing centering, the casing is pressurized to $70 \mathrm{MPa}$ and unloaded to $0 \mathrm{MPa}$. After cyclic loading 5 times, the cement sheath interface is not damaged, and there is no annular air channeling.

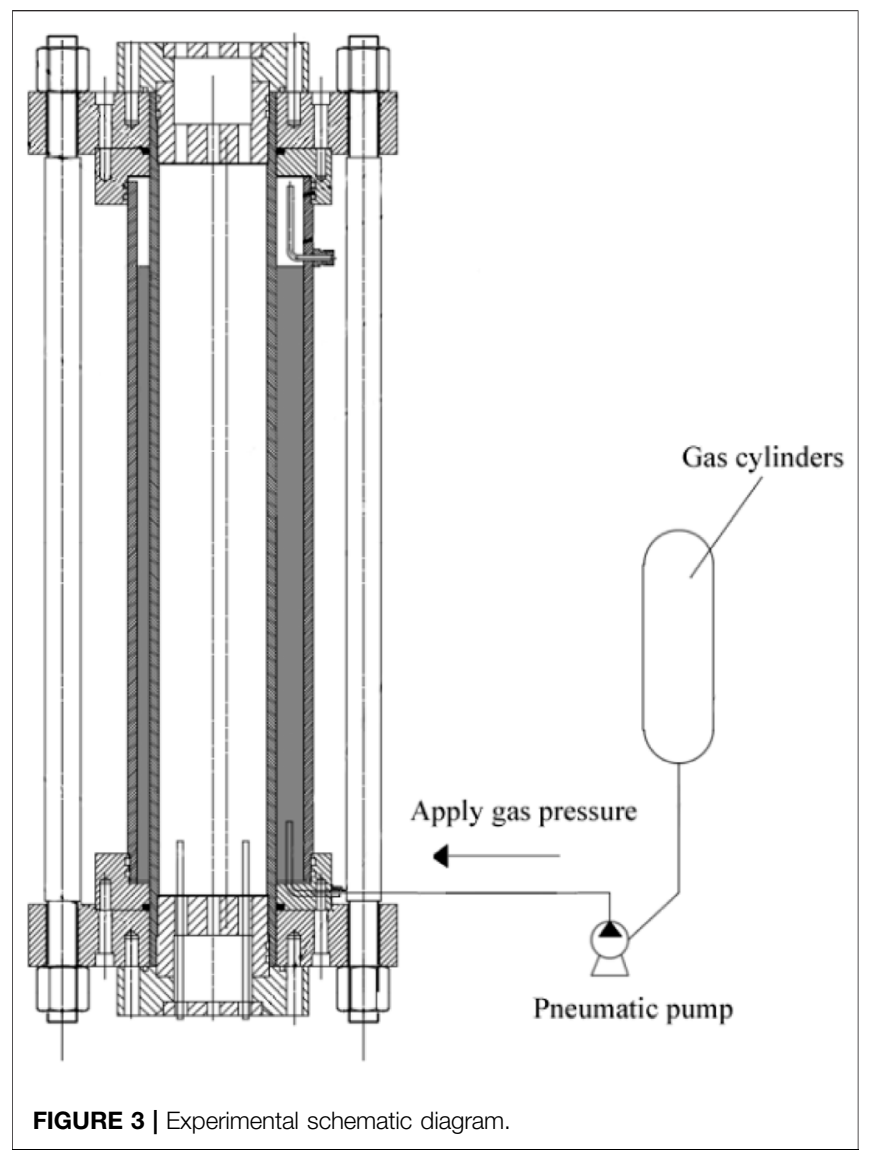

The finite element numerical simulation method is used to analyze the experimental results of cement sheath sealing integrity under the experimental conditions. The numerical simulation results are shown in Figure 5.

Figure $\mathbf{5 A - D}$ are the simulation results when the centering degree is $100 \%, 75 \%, 67 \%$ and $50 \%$, respectively. With a decrease in the centering degree of the casing, there is an obvious stress concentration in the weak part of the cement sheath. Compared with complete centering, the mise stress when the centering degree is 50\% increases by more than half. The results show that for pressurization 


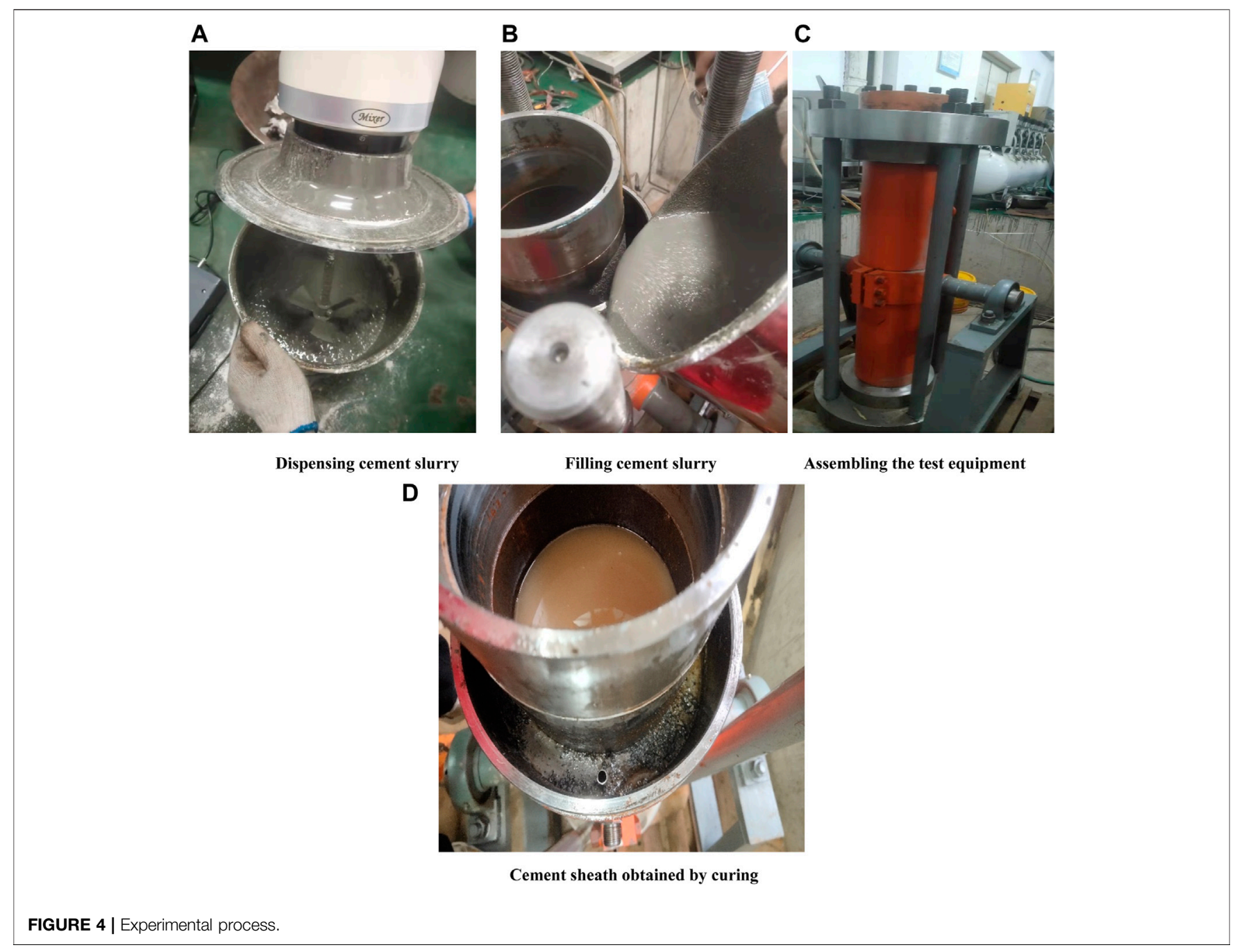

TABLE 5 | Experimental results of the influence of casing internal pressure on sealing integrity under the casing eccentricity.

\begin{tabular}{|c|c|c|c|}
\hline Casing centering (\%) & $\begin{array}{l}\text { Variation value in casing } \\
\text { (MPa) }\end{array}$ & Loading times & $\begin{array}{c}\text { Gas emission from } \\
\text { the upper end } \\
\text { face of the } \\
\text { cement sheath }\end{array}$ \\
\hline 50 & $0 \rightarrow 60 \rightarrow 0$ & Load once & give off steam \\
\hline 67 & $0 \rightarrow 60 \rightarrow 0$ & Load once & give off steam \\
\hline 75 & $0 \rightarrow 70 \rightarrow 0$ & Cycle 5 times & Not angry \\
\hline 100 & $0 \rightarrow 70 \rightarrow 0$ & Cycle 5 times & Not angry \\
\hline
\end{tabular}

in the casing, casing centering is of great significance to ensure the integrity of the cement sheath.

\subsection{Pressure Relief in Casing}

According to the experimental scheme in Table 2, the experiment on the impact of pressure relief in the casing on the sealing integrity of the cement sheath under the condition of casing eccentricity is performed, which is divided into two cases: preset annular pressure in the early stage and non-preset annular pressure. For the case of preset annular pressure in the early stage, a certain pressure is applied in the annulus during the cement slurry curing stage, and the annular pressure is released $24 \mathrm{~h}$ after the cement slurry solidifies. The experimental results are shown in Table 6.

The results show that the eccentricity of casing has little effect on the sealing failure of cement sheath caused by unloading in casing when the preset annular pressure is not applied. However, when the preset annular pressure is applied, with an increase in the casing centering, the resistance of cement sheath to annular air channeling 
A

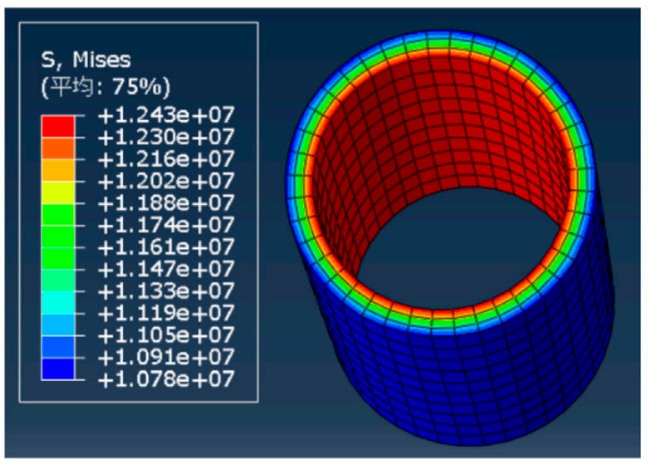

$100 \%$

C

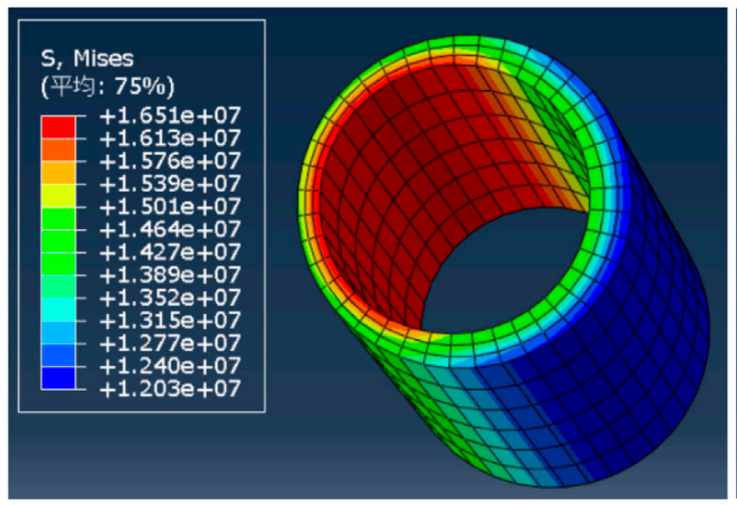

$67 \%$
B

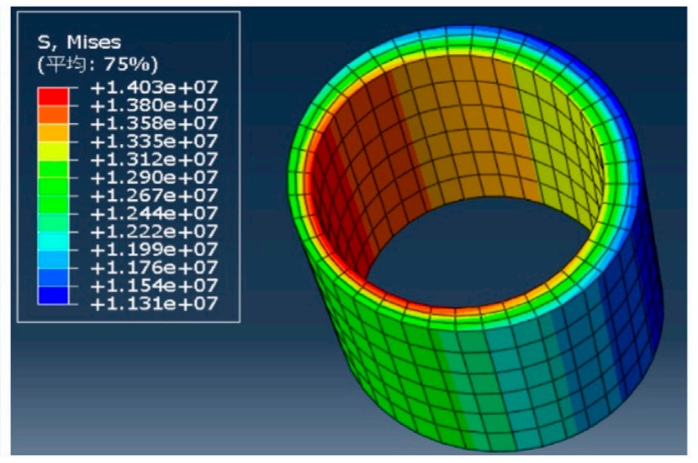

$75 \%$

D

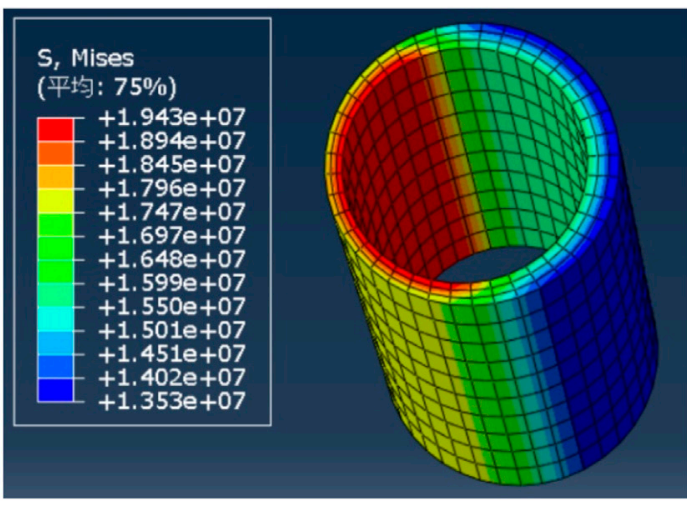

$50 \%$

FIGURE 5 | stress distribution under different conditions.

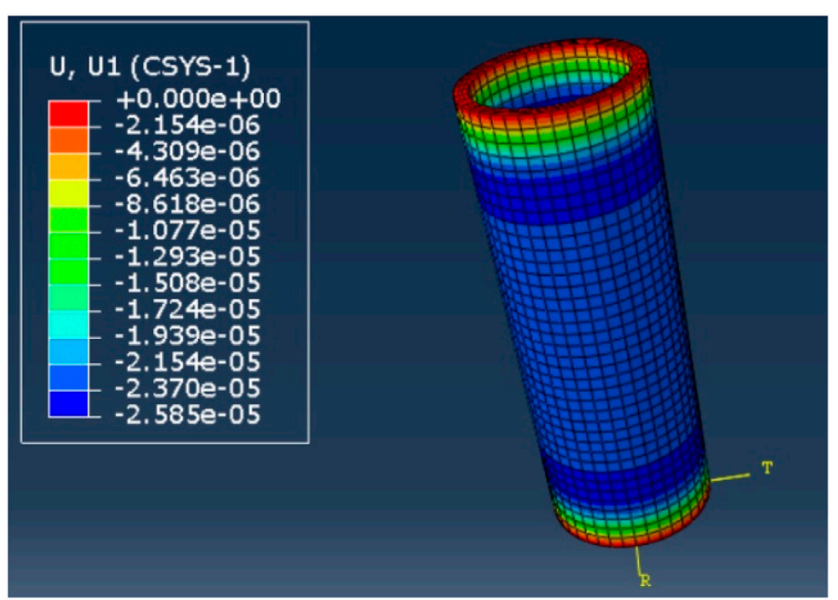

FIGURE 6 | Calculation results of the casing displacement.

caused by unloading in casing is enhanced. In this case, casing centering is of great significance to ensure the sealing of the cement sheath.
The finite element numerical simulation method is used to analyze the experimental results of the cement sheath sealing integrity under the experimental conditions. It is discussed in two cases: 0 and $10 \mathrm{MPa}$ preset in the annulus.

First, the influence of an annular pressure of $10 \mathrm{MPa}$ on the stress distribution of the cement sheath is obtained via numerical simulations. The specific steps are as follows:

Step (1): Establish the finite element model of the casing, apply a $10 \mathrm{MPa}$ pressure on the outer wall of the casing, and calculate the displacement generated by the annular pressure on the outer wall of the casing. The calculation results are shown in Figure 6:

Step (2): According to the calculation results, the preset stress of the $10 \mathrm{MPa}$ annulus will cause a $0.024 \mathrm{~mm}$ displacement of the outer wall of the casing. When the preset stress is unloaded, the casing will squeeze the solidified cement sheath and apply a load in the casing. The load size is constantly adjusted to determine the load size that produces the same displacement as in step (1) and makes an equivalent replacement.

Step (3): Apply a load consistent with that in step (2) in the casing-cement sheath-casing model and read the stress of the cement sheath based on the stress at the first interface. The stress of the cement sheath obtained by the above method is shown in Figure 7: 
TABLE 6 | Effect of the pressure relief in casing on the sealing integrity under casing eccentricity.

\begin{tabular}{|c|c|c|c|}
\hline $\begin{array}{l}\text { Preset } \\
\text { annulus pressure (MPA) }\end{array}$ & Casing centering (\%) & $\begin{array}{l}\text { Unloading in casing } \\
\text { (MPa) }\end{array}$ & $\begin{array}{c}\text { Gas emission from } \\
\text { upper end face } \\
\text { of cement sheath }\end{array}$ \\
\hline \multirow[t]{4}{*}{0} & 50 & $50 \rightarrow 36$ & give off steam \\
\hline & 67 & $50 \rightarrow 34$ & give off steam \\
\hline & 75 & $50 \rightarrow 33$ & give off steam \\
\hline & 100 & $50 \rightarrow 35$ & give off steam \\
\hline \multirow[t]{4}{*}{10} & 50 & $50 \rightarrow 28$ & give off steam \\
\hline & 67 & $50 \rightarrow 24$ & give off steam \\
\hline & 75 & $50 \rightarrow 22$ & give off steam \\
\hline & 100 & $50 \rightarrow 21$ & give off steam \\
\hline
\end{tabular}

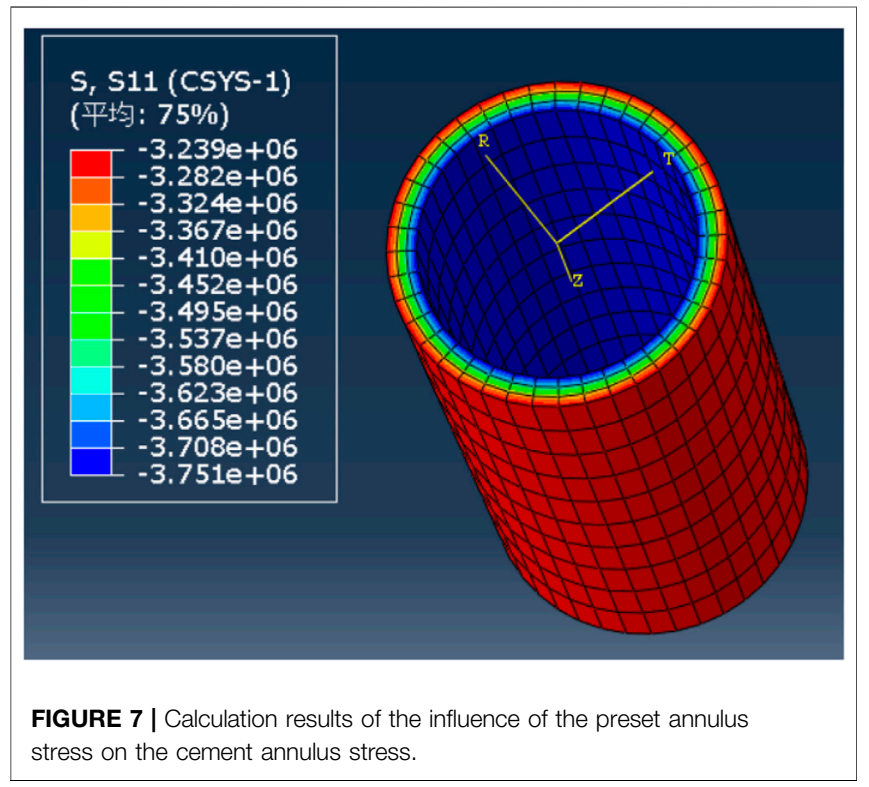

Step (4): According to the calculated stress results, set the stress of $-3.7 \mathrm{MPa}$ at the interface between the casing and cement sheath for the next calculation.

The casing centering degree is $75 \%$, and the casing internal pressure is reduced by $25 \mathrm{MPa}$ under the two cases. The numerical simulation results are shown in Figure 8.

The damage coefficient SDEG of the cement sheath interface is used to measure the sealing failure of the cement sheath interface. SDEG represents the stiffness decline rate of cohesive element. When the stress meets the damage initiation criterion, the interface begins to cause damage and the stiffness decreases, and the SDEG increases. The damage initiation criterion used in the model is as follows:

$$
\left\{\frac{\sigma_{n}}{\sigma_{n}^{0}}\right\}^{2}+\left\{\frac{\sigma_{s}}{\sigma_{s}^{0}}\right\}^{2}+\left\{\frac{\sigma_{t}}{\sigma_{t}^{0}}\right\}^{2}=1
$$

Where, $\sigma_{n}{ }^{\mathrm{o}} 、 \sigma_{s}{ }^{\mathrm{o}} 、 \sigma_{t}^{\mathrm{o}}$ represent the strength of the cementing surface in three directions respectively. If the displacement on both sides of the interface further increases and the cementation

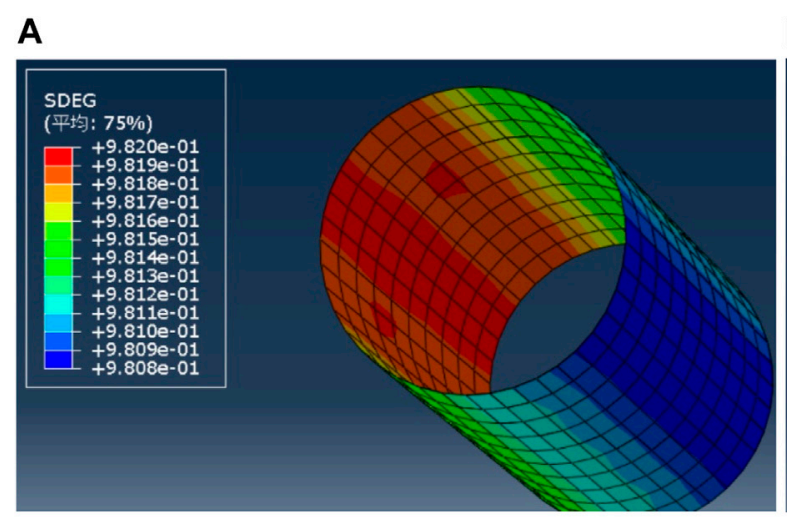

Annular preset pressure of 0 MPa
B

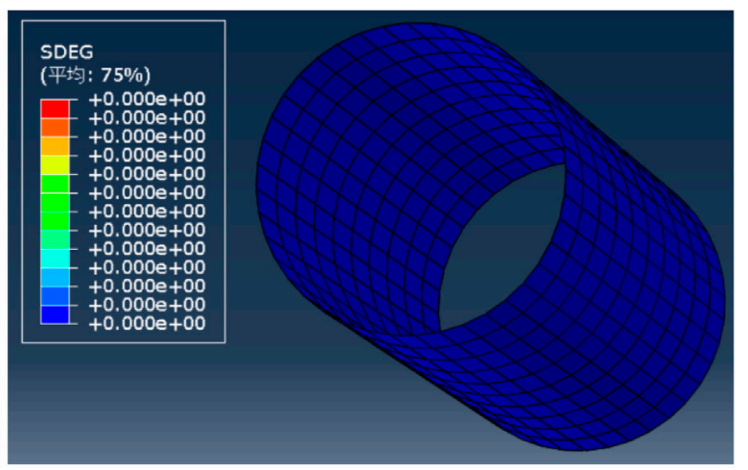

Annular preset pressure of $10 \mathrm{MPa}$

FIGURE 8 | Simulation results of pressure relief in casing. 
failure eventually occurs, the interface stiffness decreases to 0 and the SDEG reaches 1 . So, when $0<$ SDEG $<1$, the cement sheath interface is damaged, and when SDEG $=1$, the cement sheath interface is completely damaged. Figure $\mathbf{8 A}$ shows the simulation results of the non-preset pressure in the annulus, and Figure $\mathbf{8 B}$ shows the simulation results of the preset $10 \mathrm{MPa}$ pressure in the annulus. The results show that when the preset pressure of the annulus is 0 , the damage coefficient of the cement sheath interface tends to be close to 1 , and the cement sheath interface tends to be completely damaged. However, when the preset pressure of the annulus is $10 \mathrm{MPa}$, the cement sheath interface is not damaged. Therefore, applying the preset pressure of the annulus can, to a certain extent, effectively improve the sealing capacity of the cement sheath and prevent damage to the cementation interface due to casing depressurization.

\section{CONCLUSION}

1) When loading in the casing, the eccentricity of the casing has an important impact on the sealing failure of the cement sheath. Due to the stress concentration at the thin-walled cement sheath, plastic deformation easily occurs at the thin-walled cement sheath, resulting in sealing failure of the cement sheath. The centering degree of the casing that ensures the sealing integrity of the cement sheath should be greater than $75 \%$.

2) When the pressure in the casing decreases, the casing eccentricity has no obvious effect on the sealing integrity of the cement sheath when the annular pressure is not preset. When the same annular pressure is preset, the sealing integrity of the cement sheath is more likely to be damaged with an increasing casing eccentricity.

\section{REFERENCES}

Andrade, J. D., Sangesland, S., Skropa, R., Todorovic, J., and Vralstad, T. Experimental Laboratory Setup for Visualization and Quantification of Cement-Sheath Integrity [R]. SPE 173871, 2016. doi:10.2118/173871-PA

Arjomand, E., Bennett, T., and Nguyen, G. D. (2018). Evaluation of Cement Sheath Integrity Subject to Enhanced Pressure. J. Pet. Sci. Eng. 170, 1-13. doi:10.1016/j. petrol.2018.06.013

De Andrade, J., and Sangesland, S. (2016). Cement Sheath Failure Mechanisms: Numerical Estimates to Design for Long-Term Well Integrity. J. Pet. Sci. Eng. 147, 682-698. doi:10.1016/j.petrol.2016. 08.032

De Andrade, J., Torsæter, M., Todorovic, J., Opedal, N., Stroisz, A., and Vralstad, T. (201). Influence of Casing Centralization on Cement Sheath Integrity during Thermal Cycling[R]. SPE. 168012. doi:10.2118/168012-MS

Gao, D., and Liu, K. (2019). Progresses in Shale Gas Well Integrity Research[J]. Oil Gas Geology. 40 (03), 156-169. doi:10.11743/ogg20190315

Goodwin, K. J., and Crook, R. J. (1992). Cement Sheath Stress Failure. SPE Drilling Eng. 7 (04), 291-296. doi:10.2118/20453-pa

Ladva, H. K., Craster, B., Jones, T. G., Goldsmith, G., and Scott, D. (2004). The Cement-To-Formation Interface in Zonal Isolation[J]. SPE Drilling and Completion 20, 186-197. doi:10.2118/0805-0041-JPT

Li, Y., Zhang, W., Jiang, W., Yang, Y., Zhang, G., and Yang, h. (2020). Evaluation Experimental Study of Iso-Lation Ability of Cement Sheath for HTHP Gas Well [J]. Drilling Prod. Tech. 43 (02), 23-26. doi:10.3969/J.ISSN.1006-768X.2020. 02.06

\section{DATA AVAILABILITY STATEMENT}

The raw data supporting the conclusion of this article will be made available by the authors, without undue reservation.

\section{AUTHOR CONTRIBUTIONS}

All the authors conceived and designed the study. Investigation, YW; Writing—original draft, ZL; Writing—review and editing, $\mathrm{RX}$ and ZW.

\section{FUNDING}

This study received funding from CNOOC Research Institute Co., Ltd. the funder was not involved in the study design, collection, analysis, interpretation of data, the writing of this article or the decision to submit it for publication. All authors declare no other competing interests.

\section{ACKNOWLEDGMENTS}

The authors gratefully acknowledge the CNOOC scientific research project "Study of risk assessment and countermeasures of well drilling and completion under ultra-high temperature and high pressure" and "Research on development feasibility of LS25-1 gas field" (Grant Nos. YXKYZX-09-2021, 2020FS-08).

Liu, K., Gao, D., and Dahi Taleghani, A. (2018). Impact of Casing Eccentricity on Cement Sheath[J]. Energies 11 (10). doi:10.3390/en11102557

Liu, Y., Yan, H., Yu, X., Feng, Y., and Fan, W. (2014). Negative Impacts of Borehole Pressure Change on Cement Sheath Sealing Integrity and Countermeasures [J]. Nat. gas industry 34 (04), 95-98. doi:10.3787/j.issn. 1000-0976.2014.04.015

Pang, B., Song, Y., Dou, Y., and Wang, Y. (2009). Influence of Casing Wear and Cement Sheath Defect Location on Casing Stress [J]. China Pet. machinery 37 (10), 1-3.

Rossine Medeiros de Souza, W., Bouaanani, N., Eduardo Martinelli, A., and Bezerra, U. T. (2018). Numerical Simulation of the Thermomechanical Behavior of Cement Sheath in wells Subjected to Steam Injection [J]. J. Pet. Sci. Eng. 167. doi:10.1016/j.petrol.2018.04.023

Shadravan, A., Schubert, J., Amani, M., and Teodoriu, C. (2015). Using FatigueFailure Envelope for Cement-Sheath-Integrity Evaluation. SPE Drilling \& Completion 30 (01), 68-75. doi:10.2118/168321-pa

Song, M., Yang, F., song, S., Zou, F., Yan, X., and Yang, X. (2002). Influence of Cementing Cement Sheath on Casing Bearing Capacity [J]. Oil Drilling Prod. Tech. (04), 7-9. doi:10.13639/j.odpt.2002.04.004

Su, B., Long, G., Xu, X., Wu, Q., Ding, D., and Wang, Y. (2014). Safe Completion and Production Technology of Gas Well with Ultra Depth, High Temperature, High Pressure and High H2S Content : A Case from the Yuanba Gas Field in the Sichuan Basin [J]. Nat. gas industry 34 (07), 60-64. doi:10.3787/j.issn.1000-0976.2014.07.010

Teodoriu, C., and Krut, M. (2010). Reinicke, Carste Fichter, Pascak Wehling, Tu Clausthal, Germany. Investigations on Casing-Cement Interaction with Application to Gas and CO2 Storage Wells[R]. SPE 131336. doi:10.2118/ 131336-MS 
Wang, W., and Taleghani, A. D. (2014). Three-dimensional Analysis of Cement Sheath Integrity Around Wellbores. J. Pet. Sci. Eng. 121, 38-51. doi:10.1016/j. petrol.2014.05.024

Xie, Y., Li, X., Xu, X., Tong, C., and Xiong, X. (2016). Gas Accumulation and Great Exploration Breakthrough in HTHP Formations within YinggehaiQiongdongnan Basins [J]. China Pet. exploration 21 (4), 19-29. doi:10.3969/ j.issn.1672-7703.2016.04.003

Yang, M., Li, M., Fu, D., Wang, X., Fan, Y., and Nie, R. (2019). Effect of Cementing Quality on Casing Failure in Horizontal Section of Shale Gas Well [J]. China Pet. machinery 47 (12), 123-130. doi:10.16082/j.cnki.issn.1001-4578.2019.12.019

Yang, X., Shen, X., Wang, K., Shen, G., Geng, H., and Deng, P. (2018). Mechanical Mechanism of Tubing String Failure in Well Completion : A Case Study from One HTHP Well in the Tarim Basin [J]. Nat. gas industry 38 (07), 92-98. doi:10.3787/j.issn.1000-0976.2018.07.012

Yuan, Z., Teodoriu, C., and Schubert, J. (2013). Low Cycle Cement Fatigue Experimental Study and the Effect on HPHT Well Integrity. J. Pet. Sci. Eng. 105, 84-90. doi:10.1016/j.petrol.2013.03.006

Zeng, Y., Liu, R., Li, X., Zhou, S., Tao, Q., and Lu, P. (2019). Cement Sheath Sealing Integrity Evaluation under Cyclic Loading Using Large-Scale Sealing Evaluation
Equipment for Complex Subsurface Settings. J. Pet. Sci. Eng. 176, 811-820. doi:10.1016/j.petrol.2019.02.014

Conflict of Interest: ZL, YW, RX, and ZW were employed by CNOOC Research Institute Co., Ltd.

Publisher's Note: All claims expressed in this article are solely those of the authors and do not necessarily represent those of their affiliated organizations, or those of the publisher, the editors and the reviewers. Any product that may be evaluated in this article, or claim that may be made by its manufacturer, is not guaranteed or endorsed by the publisher.

Copyright (c) $2022 \mathrm{Li}, \mathrm{Wu}, \mathrm{Xie}$ and $\mathrm{Wu}$. This is an open-access article distributed under the terms of the Creative Commons Attribution License (CC BY). The use, distribution or reproduction in other forums is permitted, provided the original author(s) and the copyright owner(s) are credited and that the original publication in this journal is cited, in accordance with accepted academic practice. No use, distribution or reproduction is permitted which does not comply with these terms. 